\title{
How truth depends upon being
}

DOI:

10.1093/analys/anu057

\section{Document Version}

Accepted author manuscript

Link to publication record in Manchester Research Explorer

\section{Citation for published version (APA):}

Macbride, F. (2014). How truth depends upon being. Analysis, 74(3), 370-378.

https://doi.org/10.1093/analys/anu057

\section{Published in:}

Analysis

\section{Citing this paper}

Please note that where the full-text provided on Manchester Research Explorer is the Author Accepted Manuscript or Proof version this may differ from the final Published version. If citing, it is advised that you check and use the publisher's definitive version.

\section{General rights}

Copyright and moral rights for the publications made accessible in the Research Explorer are retained by the authors and/or other copyright owners and it is a condition of accessing publications that users recognise and abide by the legal requirements associated with these rights.

\section{Takedown policy}

If you believe that this document breaches copyright please refer to the University of Manchester's Takedown Procedures [http://man.ac.uk/04Y6Bo] or contact uml.scholarlycommunications@manchester.ac.uk providing relevant details, so we can investigate your claim.

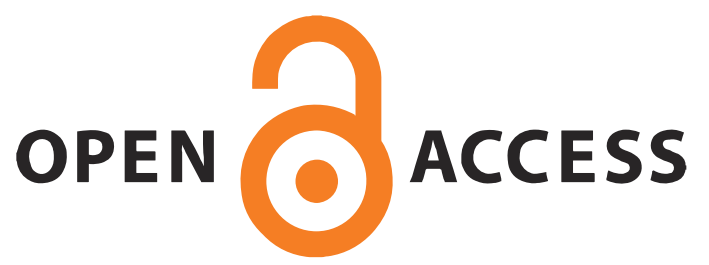




\section{How Truth Depends Upon Being}

Fraser MacBride

Draft of paper to appear in Analysis, 74 (2014), pp. 370-78

doi: 10.1093/analys/anu057

ABSTRACT: According to Armstrong (amongst others) 'any truth, should depend for its truth for something "outside" it' where this one-way dependency is explained in terms of the asymmetric relationship that obtains between a truth and its truthmaker. But there's no need to appeal to truthmakers to make sense of this dependency. The truth of a proposition is essentially determined by the interlocking semantic mechanism of reference and satisfaction which already ensures that the truth-value of a proposition depends on how things stand outside it. By contrast, how things stand outside of a proposition is determined by other worldly mechanisms that have nothing to do with truth.

KEY WORDS: truthmakers, truth, reference, satisfaction, Armstrong

\section{Introduction}

What's true depends upon how things stand but how things stand doesn't depend upon what's true. It's true that Caesar died because that's what he did but Caesar didn't throw off this mortal coil because it's true that he died; he died because Brutus and Cassius stuck in their knives. But how best to capture this asymmetry in our theoretical net?

Just suppose that truths are made true by the existence of facts, states of affairs or tropes - worldly items that, if they exist, embody how things stand. Then we may hope to explain the asymmetric dependency of truths upon how things stand by appealing to the asymmetric character of the truthmaking relation borne by truths to the worldly items that make them true. But there's no need to appeal to truthmaking to explain the asymmetric dependency of truths upon how things stand. Neither, consequently, does the asymmetric dependency of truths upon how things stand provide us with an abductive reason for supposing that there are worldly items that embody how things stand.

Why don't we need to appeal to truthmaking to explain the asymmetry? It's statements or propositions that are true or false, true or false because, inter alia, of the semantic features of words or their propositional correlates, the asymmetric connections of reference and satisfaction that hold between them and the things they are about. But how these things stand doesn't depend upon 
how words or their propositional correlates are connected to them. This already suffices to explain the asymmetric dependency of truths upon how things stand. So we don't need to appeal to the idea of truthmaking in order to account for the asymmetry in question. That's what I'm going to argue.

\section{Alternative explanations of the dependency of truth upon reality}

Armstrong has influentially advanced the view that we cannot account for the dependency of truths upon reality without truthmaking. According to Armstrong, 'any truth, should depend for its truth for something "outside" it' (2004: 7), where this dependency is to be explained by appeal to the Truthmaker Principle that every truth has a truthmaker. Armstrong conceives of a truthmaker for a truth as some portion of an independent reality in virtue of which the proposition is true; 'what makes the proposition a truth is how it stands to this reality' (2004: 5). ${ }^{1}$ Lewis was also taken with the idea that we should require 'what's true to depend upon the way the world of existing things is' (2001: 603; Bigelow 1988: 38). But he argued, against Armstrong, that there is no need to appeal to anything as strong as the Truthmaker Principle to explain the dependence of truths upon reality.

The Truthmaker Principle incorporates a commitment to worldly items whether facts, states of affairs or tropes - that embody how things stand. This is because the contingent truth that Caesar was Roman can't be true simply in virtue of the existence of Caesar, nor being Roman, nor the fusion of them. It can't be because any or all of these things could exist even if Caesar wasn't Roman. So if, as the Truthmaker Principle demands, there is something in virtue of which it's true that Caesar was Roman, something that could only exist if that was his patria, e.g. the state of affairs that Caesar was Roman. But, wary of facts, states of

\footnotetext{
${ }^{1}$ Armstrong restricts himself here to statements or propositions that aren't about statements or propositions. I will assume a corresponding restriction. It is however noteworthy that if the restriction is lifted it becomes questionable whether the truth-making relation is asymmetric. Consider, for example, the proposition that there is at least one proposition, which appears to be a proposition that makes itself true (David 2009: 153). But if the truthmaking relation cannot be relied upon to be asymmetric then it becomes questionable how far it can be relied upon to explain the asymmetric dependency of truth upon reality.
} 
affairs and tropes, Lewis recommended an alternative explanation of the dependence of truth upon reality that relies only upon a weaker principle that isn't committed to worldly items that embody how things stand: "all contingent matters supervene on what there is, together with the instantiation of the fundamental properties and relations" (Lewis 2001: 612).

Lewis's principle tells us that no two possibilities can differ about what's true unless they differ in what things there are or how they're arranged. By contrast to the Truthmaker Principle, this principle avoids commitment to facts, states of affairs or tropes. For there to be no difference in the truth-value of the proposition that Caesar was Roman without a difference in what things there are or how they're arranged it's only required that that proposition couldn't have had a different truth-value unless Caesar hadn't existed (a difference in what things there are) or his father hadn't come from Rome (a difference in how things are arranged) - or whatever this amounts to in terms of the instantiation of fundamental properties and relations. It isn't required that there's something else, the state of affairs that Caesar was Roman, something guaranteed to wax or wane whenever the proposition switches truth-value. ${ }^{2}$

Whilst Lewis's principle is weak enough to avoid commitment to worldly items that embody how things stand it is also too weak to account for the sense in which truth depends upon reality but not vice versa. This is because the supervenience between truth and reality is two-way. It is the case that no two possibilities can differ about what's true unless they differ in what there is or how things are arranged. But it's also the case that no two possibilities can differ in what there is or how things are arranged unless they differ in what's true. As Armstrong pointed out, 'not only does truth supervene upon being, but being supervenes upon truth. For if anything that has being did not have being, then something that is true would not be true. The supervenience is symmetrical' (2004: 8). But because the supervenience runs both ways it can't be used to

\footnotetext{
${ }^{2}$ Lewis's rejection of states of affairs, facts, etcetera rests upon his underlying Humeanism. This connection is explored in further detail in MacBride 2005, Beebee \& MacBride 2014. Lewis also argues that the notion of truthmaking doesn't involve a substantial notion of truth, but should be combined with a deflationary theory. I argue that Lewis is wrong (MacBride 2013): we need to acknowledge truth as a substantial relations if we're to have reason to endorse the myriad instances of the Truthmaker Principle.
} 
articulate the asymmetric sense in which truth depends upon reality (RodriguezPereyra 2005: 19).

A similar difficulty afflicts attempts to explain this dependence by deducing the truth of a proposition from a premise about how things are - by deducing the truth of the proposition that $p$ from $p$ via the schema that the proposition that $p$ is true iff $p$ (Horwich 1998: 105; 2008: 265-6). But if we can construct a deduction that goes one direction, we can construct another that goes the other: for $p$ can also be deduced from the proposition that $p$ is true via the same schema (Künne 2003: 151-2; Rodriguez-Pereyra 2005: 27).

Other attempts to understand the dependence of truth upon reality succeed in identifying asymmetries, but how they bear upon the dependency of truth upon reality remains unclear. Hornsby points out 'that sometimes it is no good answering the question Why s? by saying BECAUSE $t$ unless $s$ 's being the case requires something more than $t^{\prime}$ s being the case' (Hornsby 2005: 44). Since $p$ 's being the case requires less of the world than the truth of the proposition that $p$ - because the latter but not the former requires there to be propositions Hornsby concludes that it's appropriate to explain the truth of the proposition that $p$ in terms of its being the case that $p$, but not the other way around. But Hornsby's reflections can't take us all the distance we need to travel; they don't explain how the truth of the proposition that $p$ depends upon its being the case that $p$ - they only get so far as to establish that a (plausible) necessary condition of one thing explaining another is fulfilled.

Dodd takes us further, but nor far enough, with the suggestion that because the identity of the proposition that $p$ is partially determined by the worldly items it's about we can't understand what is required for the proposition that $p$ to be true without already having an understanding of what it is for $p$ to be the case (2007: 398-400). But it doesn't follow, without further ado, from (i) that it's not possible to understand the proposition that $p$ without already having an understanding of what the proposition is about (because the identity of the proposition is partially determined by what it's about), that (ii) it is possible to have a grasp of what it is for $p$ to be the case without having a grasp of what it is for the proposition that $p$ to be true. It doesn't follow because whereas (i) makes a claim about understanding and reference, (ii) makes a claim about 
understanding and truth. And even if a connection between these claims could be forged, (ii) only expresses a view concerning the order of understanding and so the relevance of (ii) to a view concerning the order of dependence between truth and reality remains to be made out.

\section{Truthmaking: Too Blunt An Instrument}

Does this mean that the only way to account for the dependency of truth upon reality is to appeal to the asymmetry of the truthmaking relation, as, for example, Rodriguez-Pereyra has claimed (2005: 31)? No, because there is an alternative account of the dependency that has been overlooked. But even before we consider this alternative, we ought already to be wary of truthmaking.

Truthmaking is supposed to be an asymmetric relation that holds between a worldly item (or items) that encodes how things stand, e.g. a state of affairs, and a truth-bearer, a proposition. But before we can incorporate truthmaking into our general scheme of things with a clear scientific conscience we need some questions answered first. ${ }^{3}$ What enables or equips a state of affairs to be a truthmaker for one proposition rather than another? What suits the state of affairs that $p$ to be a truthmaker for the proposition that $p$ rather than the proposition that $q$, where the proposition that $p$ and the proposition that $q$ are mutually independent?

It's tempting to declare: of course the state of affairs that $p$ is suited to make the proposition that $p$ true rather than the proposition that $q$; they were made for each other, that's why we call them by the same name. This would be readily explicable if talking about the state of affairs that $p$ was just another way of talking about the truth of the proposition that $p$ ( $c f$. Strawson 1950: 137). But if the truthmaking relation is asymmetric - as it must be if we're to use this relation to account for the asymmetric sense in which truth depends upon reality - then when we talk about the state of affairs that $p$ and the proposition that it makes true we must be talking about distinct things.

What then does entitle us to call them by the same name even though they're distinct? Propositions are descriptive of the world - some describe truly,

\footnotetext{
${ }^{3}$ Similar, equally difficult, questions for other candidate truthmakers, e.g. tropes, will need answering too (see MacBride, forthcoming).
} 
others falsely - so perhaps the state of affairs that $p$ is just what the proposition that $p$ describes. But if it's not to be mysterious how a proposition describes the state of affairs that things stand thus-and-so, the proposition that things stand thus-and-so must be articulate. It must have sufficient structure to encode those things standing thus-and-so rather than so-and-thus. And, correspondingly, if a state of affairs is to satisfy such a description, it must have sufficient structure to make it the state of affairs that fits that description rather than another. Indeed that's how states of affairs are usually conceived, as being structured entities distinguished by the manner in which they're built up from their constituents.

The problem is that the truthmaking relation is too blunt an instrument to be responsive to either the structure of propositions or the structure of states of affairs. Suppose that $a$ is a simple thing and $F$ is one of its fundamental properties. Since the proposition that $a$ is $F$ isn't true in virtue of the existence of $a$ or the existence of $F$ or the existence of them both, neither $a$ nor $F$ nor $a$ and $F$ can bear the truthmaking relation to the proposition that $a$ is $F$. There is only one worldly item, the state of affairs that $a$ is $F$, capable of making it true that $a$ is $F$. So only it is capable of serving as the first term of the truthmaking relation. Similarly the truthmaking relation can only be borne by that state of affairs to the proposition that $a$ is $F$ insofar as that proposition is also a unitary, single item. This is because nothing less than a proposition is capable of being true and only something that is capable of being true can be made true. So only $i t$, the proposition, is capable of serving as the second term of the truthmaking relation. Because the truthmaking relation only holds between the state of affairs that $a$ is $F$ and the proposition that $a$ is $F$, the truthmaking relation cannot itself connect the state of affairs and the proposition in virtue of their internal structure. This would involve the truthmaking relation holding amongst the constituents of the state of affairs and the proposition and we have established that the truthmaking relation does no such thing. The truthmaking relation just lacks the logical multiplicity required to reach inside them and light responsively upon their manifold constituents.

Of course this difficulty can be ducked by denying that propositions and states of affairs have any structure. But then we shall not only have to deny a very natural conception of propositions and states of affairs, we shall have to 
provide another account of what suits the states of affairs that $p$ to be the truthmaker for the proposition that $p$, and it is entirely unclear what that account could be if states of affairs and propositions are simples.

No doubt it is also tempting to assume that a perspicuous answer to the question what suits the state of affairs that $a$ is $F$ to be the (minimal) truthmaker for the proposition that $a$ is $F$ will be forthcoming once we attend to other, semantic, asymmetric relations that obtain between constituents of the proposition that $a$ is $F$ and the constituents of the state of affairs that $a$ is $F$ because, e.g., a constituent of the proposition that $a$ is $F$ refers to $a$ and $a$ is a constituent of the state of affairs that $a$ is $F$, and so on. But so far from illuminating the manner in which a state of affairs makes a proposition true, appealing to such relations has only the effect of obviating the need to admit truthmaking in the first place.

\section{New Solution: Truth, Reference and Satisfaction}

What we need to get into focus is the contribution of words (or their propositional correlates) to the truth and falsity of the statements we make or propositions that we express. It's because the words or their propositional correlates stand in significant relations to things in the world, things which perform a role in the semantic mechanism whereby the truth of the proposition expressed is determined, that the truth of the proposition expressed depends upon how those things stand 'outside' it (to use Armstrong's expression).

To understand this mechanism we need to appreciate the constitutive connections that Tarksi made out between the semantic notions of truth, reference and satisfaction (Tarski 1944, Field 1972). Focus on singular statements that are made using a name and a monadic predicate. The truth-value of such a statement is determined solely by whether the referent of its name (or its propositional correlate) satisfies its predicate (or its propositional correlate). This supplies all that we need by way of an explanation of the truth-value of the statement made or the proposition expressed without our having to rely upon worldly items that embody how things stand. Consider a statement made or a proposition expressed using the sentence 'Fred is a woman'. Suppose that some worldly item $i$ is the referent of 'Fred' (or its propositional correlate). Then the 
truth or falsity of this statement or proposition turns upon how things stand with $i$. Now something satisfies 'is a woman' (or its propositional correlate) if and only it is a woman. So if $i$ really is a woman then the statement or the proposition is true; otherwise it's false. This explanation of how the truth-value of the statement or the proposition expressed is determined shows us how its truth-value depends upon reality. It tells us how the statement or proposition's being true or false depends upon whether Fred is or isn't a woman. But it doesn't require us to invoke e.g. the state of affairs that Fred is a woman.

That an explanation of how truth depends upon reality has thereby been provided won't be apparent if we fail to appreciate that satisfaction is just as much a substantial relation that hooks words (or their propositional correlates) up to the world outside of a statement (or a proposition) as reference, i.e. if instead we think of saying that something satisfies 'is a woman' (or its propositional correlate) if and only if it is a woman as just shuffling words around. But saying this isn't just shuffling words (or propositional correlates) around. It's women themselves, all and only them, flesh-and-blood creatures, that stand in the satisfaction relation to the predicate 'is a woman' (or its propositional correlate) and this is a non-trivial feature of English since the predicate might have been used to apply to different things or to express a different sense.

That the explanation doesn't invoke states of affairs won't be apparent either for someone who insists upon thinking of a true statement or proposition as a description of a state of affairs that makes it true in the way that a referring expression or a descriptive phrase may be used to pick out a thing. It won't be apparent because an explanation of the truth of the proposition that Fred is a woman will itself make use of the true proposition that Fred is a woman. So if the assumption is granted that true statements or propositions are descriptions of the states of affairs that make them true then states of affairs will have been invoked after all. But sentences that are used to express propositions have a profoundly different logical and grammatical role in language from referring expressions or descriptive phrases; witness the unique capacity of sentences to be used to say something truth-evaluable. So it cannot be assumed at the outset that, despite logico-grammatical appearances, they operate in essentially the 
same manner. Of course if the Truthmaker Principle is true then we have reason for conceiving of the statements made or the propositions expressed using sentences as descriptions of the states of affairs that make them true. But whether the Truthmaker Principle is itself true is precisely the question at issue. According to Armstrong et al we need to acknowledge the Truthmaker Principle to account for the dependence of truth upon reality. But the present account doesn't assume the Truthmaker Principle but explains how truth depends upon reality only via reference and satisfaction. Evidently there can be no entitlement at this point to assume the Truthmaker Principle because that very principle is obviated by the explanation given.

It may nevertheless appear that this account of how truth depends upon reality in terms of reference and satisfaction is afflicted by the same two way problem that beset Lewis's attempts to avoid truthmaking. We can just as readily reason in the reverse direction: if the statement made or proposition expressed by using the sentence 'Fred is a woman' is true, and we appreciate the significance of combining a name with a predicate and know what 'Fred' on this occasion picks out and what it takes for something in the world to satisfy 'is a woman', then we can also figure out from the truth of the statement made that Fred is a woman. But this doesn't show that Fred's being a woman depends upon the truth of the statement made or the proposition expressed.

Consider the following analogy. We can just as easily figure out from Fred's being a sibling that her parents had another child. But this doesn't show that her parents' having another child depends upon Fred's being a sibling. Why not? Because it's already information built into what it is for someone to be a sibling that his or her parents have another child. We can figure out from Fred's being a sibling that her parents had another child because we're just unpacking the information that was already packed in.

Similarly, it's already information built into what it is for a statement made or proposition expressed using the sentence 'Fred is a woman' to be true that the referent of the name (or its propositional correlate) satisfies the predicate (or its propositional correlate). It is already built in that Fred is indeed a woman because the semantic mechanism whereby the truth of the statement or proposition expressed is determined relies upon the referent of 'Fred' (or its 
correlate) satisfying 'is a woman' (or its correlate), a contribution she is equipped to make only if she is a woman. But whilst the truth of the statement or proposition that Fred is a woman depends upon Fred's being a woman, Fred's being a woman isn't determined by a semantic mechanism but by a biological one, her having two X chromosomes.

The basic insight here is that the truth-value of a statement or proposition is essentially determined by a semantic mechanism that reaches outside of it. So although we can deduce from the truth of the proposition that $p$ that $p$ is the case, we can't (ultimately) explain its being the case that $p$ in terms of the truth of the proposition that $p$ because its being the case that $p$ is already assumed by the truth of that proposition, i.e. has already performed a role in the mechanism whereby the truth-value is determined. By contrast, its being the case that $p$ isn't determined by a semantic mechanism but by whatever worldly factors, if any, that gave rise to things being thus-and-so. So the explanation of how the truthvalue of the statement or proposition that $p$ is determined has to proceed via worldly items that the proposition represents. By contrast the explanation of its being the case that $p$ can proceed by only invoking worldly items and doesn't require mention of anything linguistic or propositional. The intuition that truth depends upon reality but reality doesn't depend upon truth reflects our nascent appreciation of this explanatory asymmetry. So acknowledging the connections between truth, reference and satisfaction that constitute this semantic mechanism equips us to understand the one-way dependence of truth upon reality without having to rely upon the idea that truths are made true. ${ }^{4}$

\section{References}

Armstrong, D.M. 2004. Truth and Truthmakers. Cambridge: Cambridge University Press.

Beebee, H. and J. Dodd. 2005. Truthmakers: The Contemporary Debate. Oxford: Oxford University Press.

\footnotetext{
${ }^{4}$ I am grateful to audiences at the Universities of Glasgow, Edinburgh and Johannes Gutenberg-Universität, Mainz. I would also like to thank Karen Bennett, Anne Bosse, Ralf Busse, Chris Daly, Julian Dodd, Ghislain Guigon, Frédérique Janssen-Lauret, Gary Kemp, Stephan Leuenberger, Kevin Mulligan, Adam Rieger and Alan Weir.
} 
Beebee, H. and F. MacBride. Forthcoming 2014. De re modality, essentialism and Lewis's Humeanism. In A Companion to David Lewis, ed. B. Loewer and J. Schaffer. Malden, MA: Wiley-Blackwell.

Bigelow, J. 1988. Real possibilities. Philosophical Studies, 53: 37-64.

David, M. 2009. Truth-making and correspondence. In Truth \& Truth-Making, ed. E.J. Lowe and A. Rami, 137-57. Stockfield: Acumen.

Dodd, J. 2007. Negative truths and truthmaker principles. Synthese, 156: 383401.

Field, H. 1972. Tarski's theory of truth. Journal of Philosophy, 69: 347-75.

Hornsby, J. 2005. Truth without truthmaking entities. In Beebee \& Dodd 2005, 33-47.

Horwich, P. 1998. Truth (2nd edn.). Oxford: Oxford University Press.

Horwich, P. 2008. Truth and being. Midwest Studies in Philosophy, 32: 258-73.

Künne, W. 2003. Conceptions of Truth. Oxford: Oxford University Press.

Lewis, D. 2001. Truth-making and difference-making. Noûs, 35: 602-15.

MacBride, F. 2005. Lewis's animadversions on the truth-maker principle. In Beebee \& Dodd 2005, 117-40.

MacBride, F. 2013. For keeping truth in truthmaking. Analysis 73: 686-95.

Rodriguez-Pereyra, G. 2005. Why truthmakers. In Beebee \& Dodd 2005, 17-31.

Strawson, P.F. 1950. Truth. Proceedings of the Aristotelian Society, 24: 129-56.

Tarski, A. 1944. The semantic conception of truth. Philosophy and Phenomenological Research, 4: 341-75. 